This item was submitted to Loughborough's Research Repository by the author.

Items in Figshare are protected by copyright, with all rights reserved, unless otherwise indicated.

\title{
Composite materials for microwave devices using additive manufacturing
}

PLEASE CITE THE PUBLISHED VERSION

http://dx.doi.org/10.1049/el.2016.0078

\section{PUBLISHER}

(c) The Institution of Engineering and Technology

\section{VERSION}

AM (Accepted Manuscript)

\section{PUBLISHER STATEMENT}

This work is made available according to the conditions of the Creative Commons Attribution-NonCommercialNoDerivatives 4.0 International (CC BY-NC-ND 4.0) licence. Full details of this licence are available at: https://creativecommons.org/licenses/by-nc-nd/4.0/

\section{LICENCE}

CC BY-NC-ND 4.0

\section{REPOSITORY RECORD}

Bukhari, Syed, William Whittow, Shiyu Zhang, and J. C. Vardaxoglou. 2019. "Composite Materials for Microwave Devices Using Additive Manufacturing”. figshare. https://hdl.handle.net/2134/21235. 
Final author version of

S. S. Bukhari, W. . Whittow, S. Zhang, and J. C. Vardaxoglou, "Composite materials for microwave devices using additive manufacturing," Electron. Lett., vol. In Press, 2016.

DOI: $10.1049 / \mathrm{el.2016.0078}$, Online ISSN 1350-911X Available online: 08 March 2016

Full paper can be found online here:

http://digital-library.theiet.org/content/journals/10.1049/el.2016.0078 


\section{Composite materials for microwave devices using additive manufacturing}

\author{
S. S. Bukhari, W. G. Whittow, S. Zhang, and J. C. \\ Vardaxoglou
}

Additive manufacturing has been combined with commercially available RF materials to synthesize composite materials whose relative permittivity can be controlled. A design equation for predicting the effective permittivity of these composite materials has also been presented. The relative permittivity of the composite materials was measured by fabricating patch antennas using these materials as the substrate. It has been demonstrated that by using Taconic, PLA and air, three materials with different dielectric constants, a large and nearly continuous range of relative permittivity values, from 1.47 to 6.00 , can be realised.

Introduction: Materials whose relative permittivity can be controlled by the designer have the potential to be employed as antenna substrates and can enhance antenna performance [1]. Such materials are also an integral part of graded index (GRIN) devices. Graded index materials have their relative permittivity locally varied in order to achieve the desired electromagnetic response. These materials have been successfully implemented in the design of a five layer flat lens using field transformation with its performance superior to that of lens designed with ray optics [2].

These materials are also essential for transformation optics which is based on the principle of transforming the original coordinate system of an electromagnetic device in such a way that its electromagnetic behaviour remains unaltered when its shape changes. This is achieved by changing the refractive index (relative permittivity and permeability) in the coordinate space by using metamaterials and other artificially designed materials [3]. Low loss magnetic materials with relative permeability other than unity are extremely difficult to manufacture therefore the refractive index is generally controlled by varying the relative permittivity. This technique has been successfully applied to design a flat hyperbolic lens. The materials were designed from micro and nanoparticles of titanates using vaccuum casting [4].

Recently additive manufacturing using stereolithography was proposed to synthesize the artificial materials with controlled relative permittivity; however the range of the relative permittivities, for the synthesized material, was found to be limited (ranging from 2.12 to 3.08) [5].

In this letter the fused deposition modelling (FDM) technique has been used. FDM is very flexible and user friendly. It uses the stereolithography file (.stl) for manufacturing the desired structure, layer by layer. The material, in molten state, is extruded from the hot nozzle which then solidifies quickly after extrusion. This letter shows that by using FDM, additively manufactured structures can be combined with commercial laminates in order to achieve a wide range of permittivities. The resulting composite materials are three phase structures because three materials with different electromagnetic properties have been used for their synthesis. This allows for a larger range of relative permittivities which can be designed and synthesized, and can create a smooth permittivity gradient.

The relative permittivity of these composite materials can be controlled by varying the ratio and individual electromagnetic properties of the constituent materials. The relative permittivity of the composite material, as shown in Figure 1, can be calculated analytically by the following equation. The equation has been derived by using Weiner bounds for a mixture of dielectrics [6]. It calculates the relative permittivity of the composite material by weighting the volumetric ratios of the constituent materials with their respective dielectric constants.

$$
\begin{gathered}
\varepsilon=\frac{\left(h_{1}\right)\left(\varepsilon_{1}\right)+k\left(h_{2}\right)\left(\varepsilon_{2}\right)+(1-k)\left(h_{2}\right)\left(\varepsilon_{3}\right)}{h_{1}+h_{2}} \\
k=\left(\frac{a}{b}\right)^{2}
\end{gathered}
$$

Where $a$ is the length of the side of a square, $b$ is the lattice constant/periodicity as shown in Figure $1 . h_{1}$ and $h_{2}$ are the thickness of the constituent materials (in this paper $h_{1}$ is the thickness of the additively manufactured structure while $h_{2}$ is the thickness of the RF laminate). $\varepsilon_{1}, \varepsilon_{2}$ and $\varepsilon_{3}$ are the relative permittivity of the constituent materials. $\varepsilon$ is the effective permittivity of the composite material.

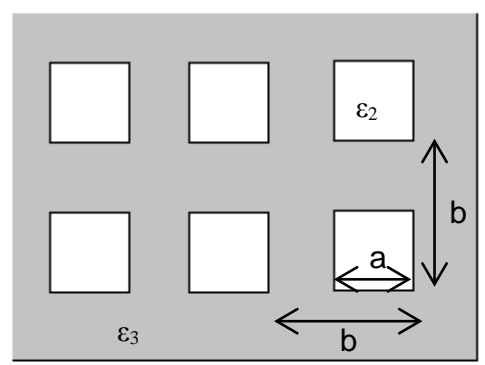

(a)

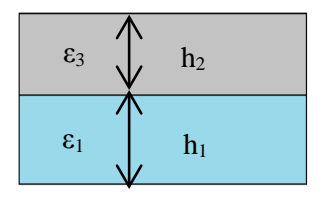

(b)
Fig. 1(a) Square lattice showing a, length of the side of each square and the lattice constant $b$. In this paper, grey indicates PLA while the white colour in the lattice shows the presence of air (b) Cross sectional view, grey shows PLA and blue shows Taconic, $h_{2}$ and $h_{1}$ are their respective thicknesses (top layer has the square lattice)

As indicated by the equation 1, the relative permittivity of these composite materials can be controlled by varying the volumetric ratios of these three materials.

Manufacturing: Composite materials were manufactured using the Makerbot Replicator 2x. The printer has a dual nozzle and a resolution of 100 microns. The material used for construction was PLA, it has a relative permittivity of 2.7 and its loss tangent value is 0.008 . The other two materials used for manufacturing composite materials presented in this paper are Taconic RF-60A (relative permittivity 6.15, loss tangent 0.0038 ) and air. RF-60A was affixed to the bed of the printer with the help of a Kapton thermal tape which also improves the adhesion of PLA to the RF-60A laminate. The bed was heated to $105^{\circ} \mathrm{C}$ and PLA was printed directly onto the laminate. Air was introduced in the composite materials in the form of a square lattice in the printed PLA structure as illustrated in Figure 2.

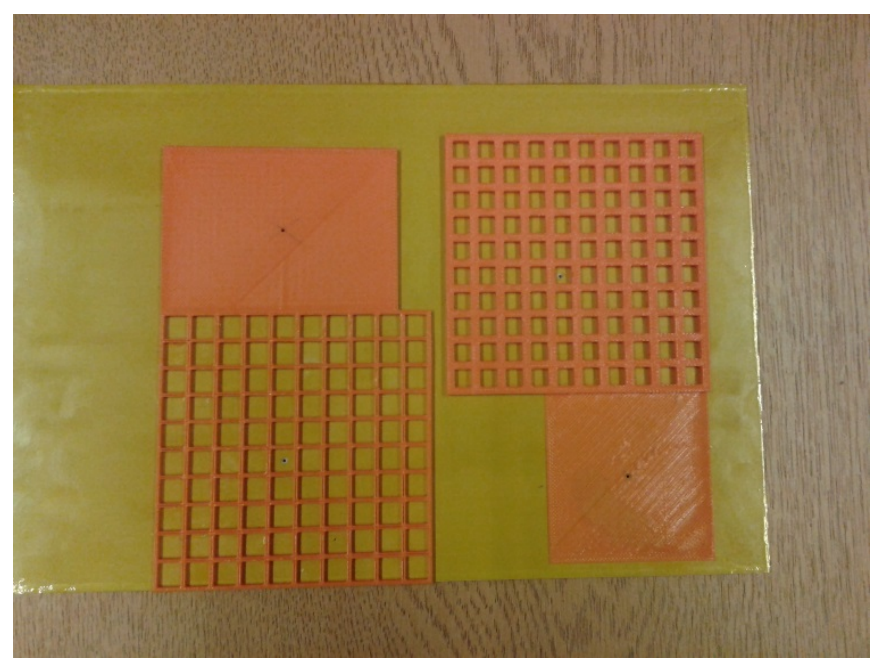

Fig. 2 Additively manufactured composite materials on printed on Taconic RF-60A laminate

Measurements: The relative permittivity of these composite materials was measured with the help of a microstrip patch antenna. The composite material was employed as a substrate with the patch antenna placed on top and the ground plane below. This technique is widely used for measuring the relative permittivities of different materials and an aperture coupled patch has been used for measuring the relative permittivity of a textured dielectric [7]. The electric fields for a patch antenna are concentrated within the substrate between the ground plane and the patch. They are very strong and perpendicular to the surfaces of the patch and the ground plane. In this work, the patches are fed with a probe and their resonant frequency was measured using a 39743Anritsu 
network analyser. The same antenna was then simulated using EMPIRE XPU, Finite difference time domain (FDTD) software, with a homogeneous substrate. The resonant frequency of the full wave FDTD simulator was then matched to the measured resonant frequency by varying the relative permittivity of the homogeneous substrate in the simulations. This led to the ascertainment of the relative permittivity of the composite material. The antenna dimensions and the substrate thickness were kept exactly the same as in the measurements. It has been demonstrated, as illustrated in Table 1, that by using composite materials the relative permittivity values ranging from 1.47 to 6 have been measured. Since all the materials used for the manufacturing of composite materials are very low loss the resulting composite material is also low loss material. Very good agreements among the measured and analytically calculated values of relative permittivity have been found, as shown in Table 1.

Table 1: Estimated and measured relative permittivity values for composite materials. $h_{1}$ is the thickness of the additively manufactured structure which consists of air and PLA, $h_{2}$ is the thickness of Taconic RF-60A laminate. The estimated relative permittivity has been calculated by using equation 1 with $\varepsilon_{1}=6, \varepsilon_{2}=1$ and $\varepsilon_{3}=2.7$. The measured relative permittivity of Taconic RF-60A was 6 which is within the specified tolerance range [8]. All lengths are in mm. Freq. is the measured resonant frequency of the patch.

\begin{tabular}{|c|c|c|c|c|c|c|c|}
\hline \multicolumn{4}{|c|}{ Parameters for (1) } & \multirow{2}{*}{$\begin{array}{c}\varepsilon \text { from } \\
\text { (1) }\end{array}$} & \multirow{2}{*}{ Meas. $\varepsilon$} & \multirow{2}{*}{$\begin{array}{l}\text { Freq. } \\
\text { (GHz) }\end{array}$} & \multirow{2}{*}{$\begin{array}{c}\text { Patch } \\
\text { Size }\end{array}$} \\
\hline$a$ & $\boldsymbol{b}$ & h1 & h2 & & & & \\
\hline 7 & 8 & 1.6 & 0 & 1.40 & 1.47 & 2.52 & $\begin{array}{c}48.5 \times \\
10\end{array}$ \\
\hline 5.6 & 8 & 2 & 0 & 1.87 & 1.83 & 2.51 & $\begin{array}{c}44 \times \\
10\end{array}$ \\
\hline 4 & 8 & 2 & 0 & 2.28 & 2.24 & 2.62 & $\begin{array}{c}38.5 \times \\
9.5\end{array}$ \\
\hline 0 & 1 & 2.4 & 0 & - & 2.70 & 2.58 & $\begin{array}{c}35.5 \times \\
10\end{array}$ \\
\hline 5.6 & 8 & 2.3 & 1.3 & 3.36 & 3.20 & 3.18 & $\begin{array}{c}25 \times \\
20\end{array}$ \\
\hline 7 & 8 & 1.3 & 1.3 & 3.70 & 3.65 & 3.77 & $\begin{array}{c}19.5 \times \\
15.5\end{array}$ \\
\hline 0 & 1 & 2.2 & 1.3 & 3.92 & 3.80 & 2.93 & $\begin{array}{c}24.5 \times \\
19 \\
\end{array}$ \\
\hline 2.5 & 5 & 0.55 & 1.3 & 4.89 & 5.10 & 3.19 & $\begin{array}{c}20.5 \times \\
16\end{array}$ \\
\hline 0 & 1 & 0 & 1.3 & - & 6.00 & 2.55 & $\begin{array}{c}24.5 \times \\
10 \\
\end{array}$ \\
\hline
\end{tabular}

Effective medium theory dictates that for a structure to behave as a homogeneous material the frequency of operation should be very much lower than the resonant frequency of the lattice. A reasonable rule of thumb is to have the lattice of order $\lambda / 10$ which has been the case for these measurements. However the measurements for the first four samples, in Table 1 , have also been taken at the lattice size of $\lambda / 7$ and it was observed that the composite material still behaves as a homogeneous structure at this size. This was achieved by using relatively smaller microstrip antennas for these samples. These antennas resonated at a higher frequency (ranging from $5 \mathrm{GHz}$ to $5.5 \mathrm{GHz}$ ) while the lattice properties were kept constant. Negligible variations in the measured relative permittivity were found for these composite materials for both lattices. It will also be possible in the future to obtain an even wider range of values of relative permittivity for composite materials, by using dual nozzle 3D printing, and suitably choosing the constituent materials with distinct electromagnetic properties.

Conclusions: Composite materials have been synthesized by combining additive manufacturing with commercially available RF materials. Fused deposition modelling has been successfully used to 3D print directly on to a Taconic RF-60A laminate. It has been demonstrated that the three phase low loss composite materials with a wide range of relative permittivity (from 1.47 to 6 ) have been manufactured. The relative permittivity of these materials was measured by using them as a substrate for patch antennas. By using Weiner bounds, an equation to predict the effective relative permittivity of these composite materials has been derived. The measured values show a very good agreement with the ones analytically calculated. The relative permittivity is controlled by varying the height and the lattice parameters of the additively manufactured structures.

S. S. Bukhari, W. G. Whittow, S. Zhang, and J. C. Vardaxoglou are with Wolfson School of Engineering, Loughborough University, Loughborough LE11 3TU, United Kingdom.

E-mail: s.s.bukhari@lboro.ac.uk

\section{References}

[1] C. C. Njoku, W. G. Whittow, and J. C. Vardaxoglou, "Simulation Methodology for Synthesis of Antenna Substrates With Microscale Inclusions,” IEEE Trans. Antennas Propag., vol. 60, no. 5, pp. 2194-2202, 2012.

[2] S. Jain, M. Abdel-Mageed, and R. Mittra, "Flat-lens design using field transformation and its comparison with those based on transformation optics and ray optics," IEEE Antennas Wirel. Propag. Lett., vol. 12, pp. 777-780, 2013.

[3] B. N. B. Kundtz, D. R. Smith, and J. B. Pendry, "Electromagnetic Design With Transformation Optics," Proc. IEEE, vol. 99, no. 10, pp. 1622-1633, 2011.

[4] O. Quevedo-Teruel, W. Tang, R. C. Mitchell-Thomas, A. Dyke, H. Dyke, L. Zhang, S. Haq, and Y. Hao, "Transformation optics for antennas: why limit the bandwidth with metamaterials?," Sci. Rep., vol. 3, p. 1903, 2013.

[5] J. Tribe, W. G. Whittow, R. W. Kay, and J. C. Vardaxoglou, "Additively manufactured heterogeneous substrates for threedimensional control of local permittivity," Electrnoic Lett., pp. 745-746, 2014.

[6] K. K. Karkkainen, "Effective permittivity of mixtures: numerical validation by the FDTD method,” IEEE Trans. Geosci. Remote Sens., vol. 38, no. 3, pp. 1303-1308, 2000.

[7] D. Psychoudakis, Y.-H. Koh, J. L. Volakis, and J. H. Halloran, "Design Method for Aperture-Coupled Microstrip Patch Antennas on Textured Dielectric Substrates," IEEE Trans. Antennas Propag., vol. 52, no. 10, pp. 2763-2765, 2004. 